\title{
THE ATTENUATION OF LIGHT IN SEA AND ESTUARINE WATERS IN RELATION TO THE CONCENTRATION OF SUSPENDED SOLID MATTER
}

\author{
By D. Jones and M. S. Wills \\ Royal Naval Scientific Service
}

(Text-figs. I-8)

Experiments have been reported recently (Atkins, Jenkins \& Warren, I954) in which the relative concentration of suspended matter at different depths in the sea was determined by filtering samples of water through collodion membranes and measuring the relative albedos. Also reported in the same paper are the results of a series of observations of the visual range of a Secchi disc at station $\mathrm{E} I$ in relation to the concentration of phytoplankton.

Experiments are now described which were designed to investigate the relation between the Secchi disc reading, the concentration of suspended matter, and the attenuation coefficient of tungsten light in sea water.

Thanks are due to the Admiralty for permission to publish this paper, and to Mrs L. M. Lewis of A.R.L. who assisted with the experimental work. The authors are also very grateful for assistance and facilities provided by the Marine Biological Association of the U.K. and by the Water Pollution Research Laboratory of D.S.I.R.

\section{Measurement of Attenuation Coefficient}

It is well known that the optical properties of a sample of natural water may be affected during collection and removal to a laboratory (Hulbert, I945; Jenkins \& Bowen, I946; Jerlov, I95I). Such measurements should therefore be made as far as possible in situ. The Admiralty Research Laboratory hydrophotometer is an instrument which may be lowered into water at any desired position, and measures the attenuation of an approximately parallel beam of light from a tungsten filament lamp traversing a path of length $50 \mathrm{~cm}$. in the water. It is somewhat similar to that developed by Pettersson (I934), the main difference being that the A.R.L. hydrophotometer has been designed to prevent as far as possible scattered light falling on the photocell. The instrument consists of a lamp-housing and a photocell-housing rigidly connected together by three tubes and may be seen in the photograph of Fig. I. A 
diagram of the optical system and the electrical circuit is given in Fig. 2. Light from the bulb $B$ is rendered parallel by the lens $L_{1}$ and passes through the $\frac{3}{8}$ in. plate glass window $W_{1}$ into the turbid water $T$. After traversing a path

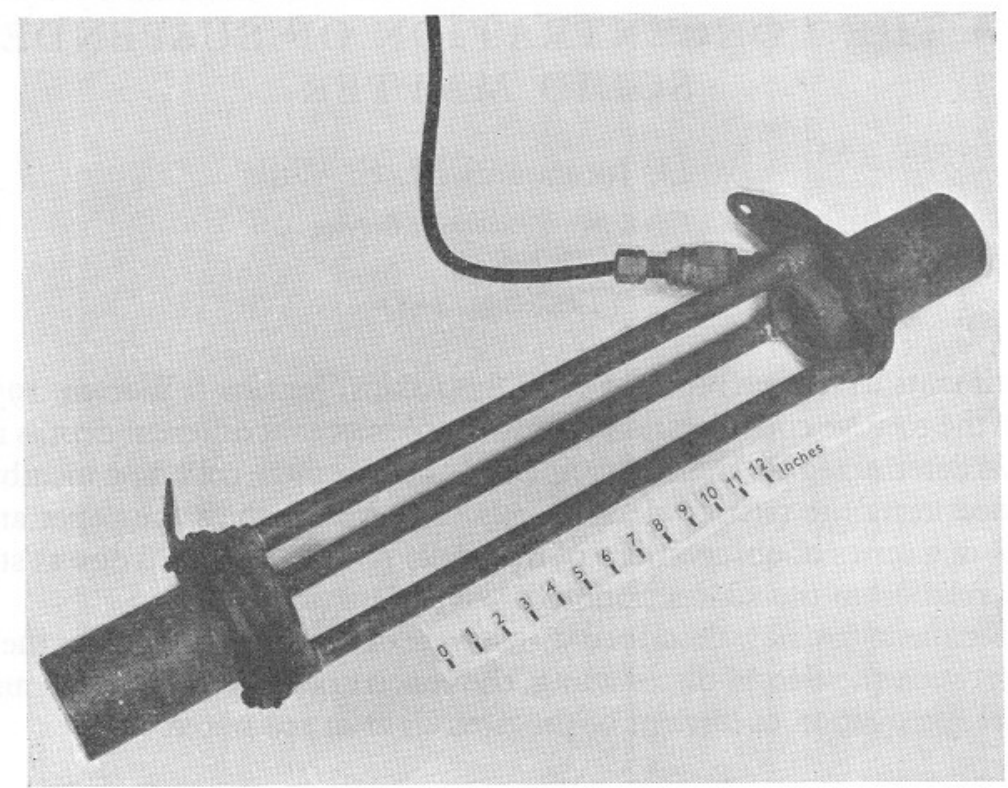

Fig. I. The A.R.L. hydrophotometer.

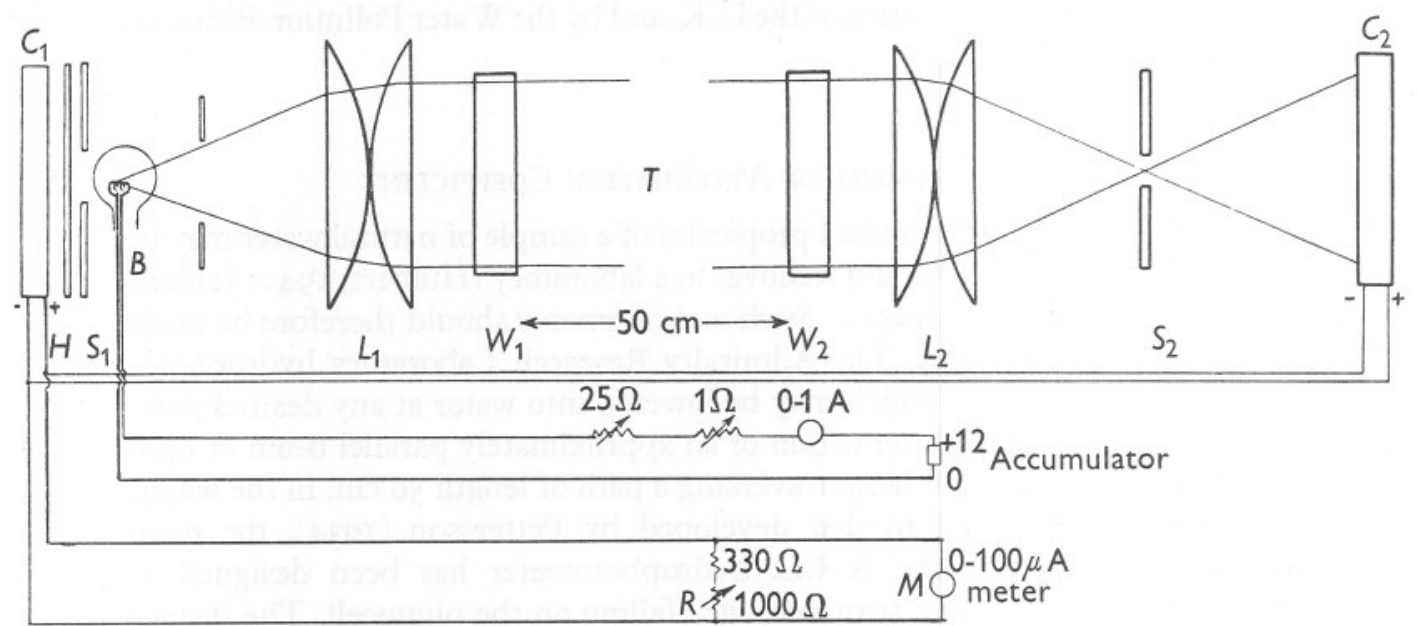

Fig. 2. Optical system and electrical circuit of A.R.L. hydrophotometer. For explanation see text. 
of length $50 \mathrm{~cm}$. the light enters the photocell-housing through the window $W_{2}$, and is brought to a focus near the plane of the stop $S_{2}$. Although the image is formed in a slightly different position according to whether the instrument is in water or in air, all the light still passes through $S_{2}$. It finally falls on a Weston barrier layer photocell $C_{2}$ which incorporates a green filter producing a spectral response approximating to that of the eye. The stop $S_{2}$ effectively prevents daylight reaching the photocell $C_{2}$, and so the instrument can be used equally well in daylight. A similar photocell $C_{1}$ is located inside the lamp-housing and a portion of the light from $B$ passes through the adjustable stop $S_{1}$ and falls on $C_{1}$. A heat-absorbing glass $H$ is necessary to minimize heating of $C_{1}$ by the lamp with consequent change of sensitivity. The two cells $C_{1}$ and $C_{2}$ are connected in opposition as shown. In the laboratory, with the instrument in air, $S_{1}$ is adjusted so that the outputs from the two cells balance. This method of design compensates for variations in intensity of the light source. Just before the instrument is used in water the light-beam is blocked from $C_{2}$ and the meter $M$ is set to full-scale deflexion (Ioo divisions) by means of the variable resistance $R$. When the instrument is immersed in water, the light transmitted increases by a factor of approximately $\mathrm{I} .08$ since two airglass reflexions are eliminated. Thus the meter reading obtained when the instrument is immersed has to be corrected, and the percentage light transmission per half metre $t$ is given in terms of the meter reading $M$ by the formula

$$
t=(\mathrm{1} 00-M) 0.92 \text {. }
$$

It is well established that the absorption and scattering of light in a turbid medium obey an exponential law, and thus an attenuation coefficient $\mu$ (metre $)^{-1}$ can be introduced given by the formula

$$
t=\mathrm{IOO} \exp (-0.5 \mu)
$$

It should be emphasized that this coefficient is not the same as the vertical extinction coefficient $\left(\mu_{v}\right)$ as found from the variation with depth in the sea of the daylight falling on an upturned horizontal surface which is defined (Poole \& Atkins, 1928) by

$$
\mu_{v}=\frac{2 \cdot 3}{d}\left\{\log _{10} V_{1}-\log _{10} V_{2}\right\}
$$

where $V_{1}$ and $V_{2}$ are the simultaneous values of the illumination at two points differing in depth by $d$ metres. This is because illumination on a horizontal surface at any depth in water is partly due to light that has been scattered by the water, whereas the attenuation coefficient refers only to a parallel beam (the instrument being designed to eliminate as far as possible the effect of scattered light). It should be mentioned, however, that owing to certain 
unavoidable limitations a little forward scattered light will always be collected by such an instrument; the error introduced as a consequence of this factor is discussed in the Appendix to this paper.

The current generated by a barrier-layer photocell is no longer proportional to the light intensity when the resistance in series with the cell is too high. It was therefore necessary to test the linearity of response of the instrument. This was done by introducing into the beam (in air) a number of thin glass plates, and measuring the change in galvanometer deflexion as each plate was added. Allowance was made for multiple reflexions between the surfaces of the plates when calculating the attenuation produced by a given number of plates. With the electrical circuit used the response was accurately linear.

\section{MEASUREMENTS WITH SUSPENSIONS MADE UP IN THE LABORATORY}

Preliminary experiments were carried out in the laboratory using suspensions of kaolin or Thames mud in tap water. The hydrophotometer was placed in a tank containing about 151 . of water. Known amounts of a concentrated suspension of kaolin (1000 p.p.m.) or Thames mud (200 p.p.m.) were stirred into the tank and the light transmission was measured at each value. In Fig. 3 is shown a graph of the attenuation coefficient per metre $(\mu)$ plotted against the concentration in $\mathrm{mg} / \mathrm{l}$. for the kaolin and Thames-mud suspensions.

\section{EXPERIMENTS AT SEA}

\section{Method of Obtaining Samples and Measurements}

In the measurements on the water at sea one end of a length of clean $\frac{1}{2}$ in. rubber hose pipe was lashed to the hydrophotometer which was then lowered into the sea from a boat. The other end of the pipe was connected to a carefully cleaned 21 . glass bottle which could be evacuated by means of an electrically driven pump running from a $24 \mathrm{~V}$ accumulator. Water was drawn up the pipe into the sample bottle and at the same time the light transmission was measured. The bottle was filled and emptied overboard at least three times before the final sample was taken.

Measurements were made at various depths down to $12 \mathrm{~m}$, and the Secchi disc visibility was also observed using a white disc of $20 \mathrm{~cm}$ diameter. The observations were made at various positions in the Thames Estuary between Gravesend and the Nore, and in the sea and estuarine waters near Plymouth. Altogether thirty-four samples of water were filtered, covering a range of light transmission from 5 to $90 \%$ per half metre. Details of the observations are given in the table of results (Table I), including light transmission measurements for some positions where no water sample was taken. The positions of the stations are shown on the maps in Figs. 4 and 5. 


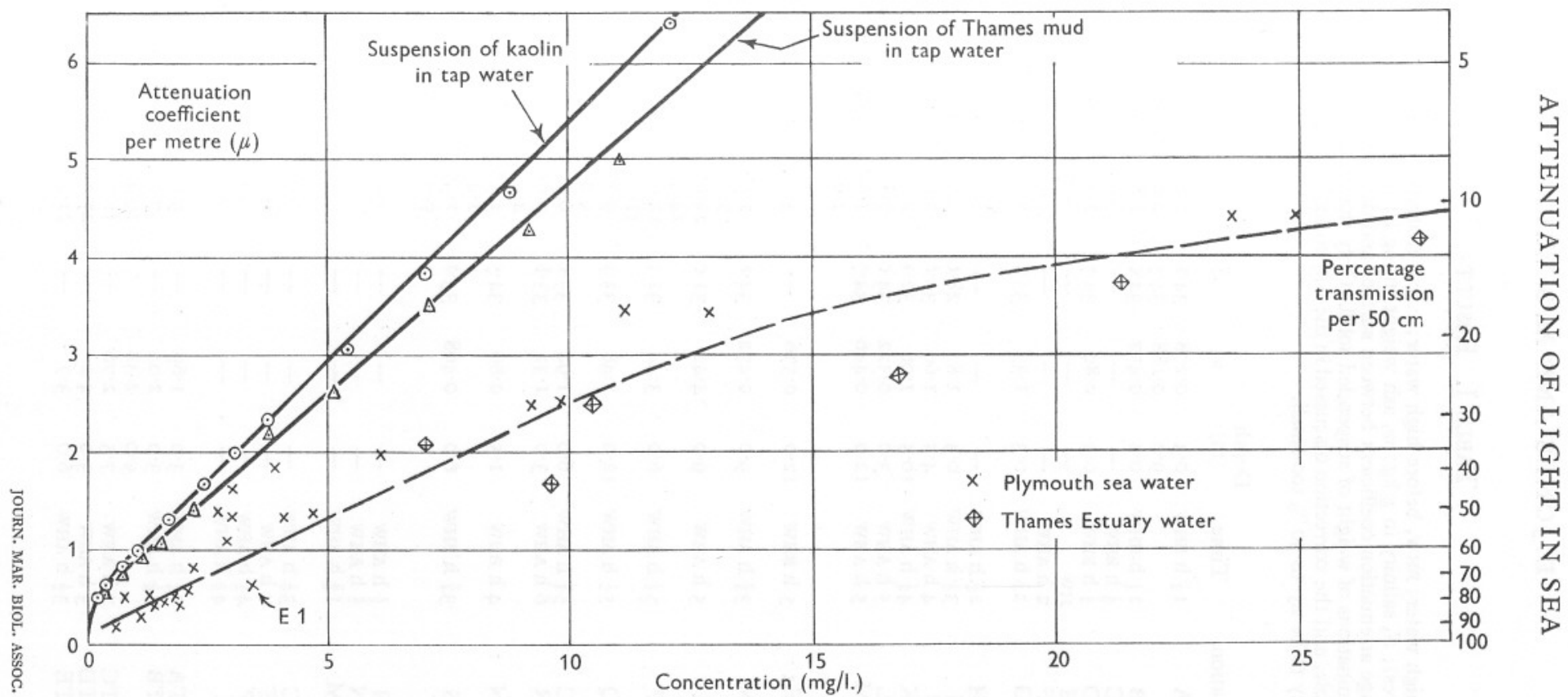

Fig. 3. Relation between attenuation coefficient per metre and concentration of suspended solid matter. 


\section{TABle I. Results}

AHw, after high water; BHw, before high water; $c$, concentration in $\mathrm{mg} / 1$.; $D$, Secchi disc visibility (metres); $S$, salinity in $\mathrm{g} / \mathrm{kg} ; w$, ash weight in $\mathrm{mg} / \mathrm{l} . ; \mu$, attenuation coefficient per metre; $\bar{\mu}$, average attenuation coefficient between surface and depth $D$; ${ }^{\star}$, indicates two independent determinations of weight of suspended solid. Only the observed values, $\mu$ and $\bar{\mu}$ are given in the table, and the correction discussed in the Appendix has not been made. Thus the values are likely to be up to $30 \%$ too small.

\begin{tabular}{|c|c|c|c|c|c|c|c|c|c|}
\hline Date & Station & Time & $\begin{array}{c}\text { Depth } \\
\text { (m) }\end{array}$ & $\mu$ & $S$ & $c$ & $w$ & $D$ & $\bar{\mu}$ \\
\hline \multirow[t]{13}{*}{ 6. v. 53} & A & $\mathrm{I} \frac{1}{2} \mathrm{~h}$ BHW & $\begin{array}{l}0.3 \\
9.0\end{array}$ & $\begin{array}{l}0.278 \\
0.188\end{array}$ & $\begin{array}{l}34 \cdot 8 \\
34 \cdot 5\end{array}$ & $\begin{array}{l}I \cdot I \\
0.6\end{array}$ & - & 2I & $\frac{0.21 I}{-}$ \\
\hline & B & I $\frac{1}{4} \mathrm{~h}$ BHW & 0.3 & 0.472 & 34.0 & $\mathrm{I} \cdot 8$ & - & I5 & 0.304 \\
\hline & C & $\frac{1}{2} \mathrm{~h}$ BHW & - & $\overline{8}$ & - & - & - & 8 & 0.56 \\
\hline & D & $\frac{1}{4} \mathrm{~h}$ BHW & 0.3 & 0.80 & $32 \cdot 7$ & $2 \cdot 2$ & - & 6.5 & 0.68 \\
\hline & $\underset{\mathrm{E}}{\mathrm{E}}$ & & - & - & - & - & - & II & 0.445 \\
\hline & $\begin{array}{l}F \\
G\end{array}$ & $\begin{array}{l}2 \mathrm{~h} \text { AHW } \\
2 \frac{1}{4} \mathrm{~h} \text { AHW }\end{array}$ & $\overline{0.3}$ & $I \cdot 35$ & $\overline{33 \cdot 6}$ & $\overline{2 \cdot 7^{\star}}$ & $\overline{0.99^{\star}}$ & 5 & $\begin{array}{l}0.89 \\
1.34\end{array}$ \\
\hline & $\mathrm{H}$ & & - & - & - & 4.7 & $I \cdot 25$ & & \\
\hline & I & 3 A AHW & 0.3 & $I \cdot 83$ & 28.6 & 3.9 & $\overline{I \cdot 4}$ & 10.5 & 0.472 \\
\hline & $\mathrm{J}$ & $4 \mathrm{~h}$ AHW & 4.5 & 1.60 & $30 \cdot 6$ & 3.0 & $\begin{array}{l}\text { I. } 4 \\
0.9\end{array}$ & $2 \cdot 5$ & I.70 \\
\hline & $\mathrm{K}$ & $41 \mathrm{~h}$ AHW & 10.5 & $I .06$ & $32 \cdot I$ & $2 \cdot 9$ & 0.9 & 2 & $\mathrm{I} \cdot 80$ \\
\hline & $\bar{L}$ & $5 \mathrm{~h} \mathrm{AHW}$ & 3.0 & 0.522 & 34.0 & $2 \cdot I$ & $\overline{0.6}$ & 3 & I.54 \\
\hline & M & $5 \mathrm{~h}$ AHW & I $2 \cdot 0$ & 0.446 & $34 \cdot 7$ & $I \cdot 6^{\star}$ & 0.5 & $\begin{array}{l}9 \\
5\end{array}$ & $\begin{array}{l}0.48 \\
0.92\end{array}$ \\
\hline & & & & & & $\mathrm{I} \cdot 9$ & & & \\
\hline II. v. 53 & EI & $5 \mathrm{~h} \mathrm{BHW}$ & $12 \cdot 0$ & 0.576 & - & 3.5 & 0.3 & 7 & 0.535 \\
\hline \multirow[t]{9}{*}{ I3. v. 53} & $\mathrm{~N}$ & $3 \frac{3}{4} \mathrm{~h}$ AHW & $9 \cdot 0$ & 0.472 & $34 \cdot 8$ & $\begin{array}{l}\mathrm{I} \cdot 9^{\star} \\
\mathrm{I} \cdot 8\end{array}$ & - & 8.5 & 0.554 \\
\hline & I & $5 \mathrm{~h} \mathrm{AHW}$ & $9 \cdot 0$ & $4 \cdot 42$ & $3 r \cdot 0$ & $23^{\cdot} \cdot 6^{\star}$ & - & I & $5 \cdot 20$ \\
\hline & $\mathrm{P}$ & $5 \frac{1}{4} \mathrm{~h}$ AHW & $6 \cdot 0$ & 3.44 & $32 \cdot I$ & $\begin{array}{l}24.9 \\
12.9^{\star}\end{array}$ & 一 & $I \cdot 5$ & 3.63 \\
\hline & 0 & $51 \mathrm{~h}$ AHW & 12.0 & 2.48 & & II $\cdot$ I & & & \\
\hline & $Q$ & $52 \mathrm{AHWW}$ & 120 & 2.48 & $33 \cdot 1$ & $\begin{array}{l}9 \cdot 7^{n} \\
9 \cdot 2\end{array}$ & - & $\mathrm{I} \cdot 75$ & 2.50 \\
\hline & C & $5 \frac{3}{4} \mathrm{~h}$ AHW & $6 \cdot 0$ & I.94 & $33 \cdot 6$ & $6 \cdot I$ & - & $2 \cdot 25$ & $2 \cdot 19$ \\
\hline & & $6 \mathrm{~h}$ AHW & $3 \cdot 0$ & $\mathrm{I} \cdot 3 \mathrm{I}$ & $33 \cdot 8$ & $\begin{array}{l}3 \cdot 0^{\star} \\
4 \cdot 1\end{array}$ & - & 3 & $I \cdot 3 I$ \\
\hline & $\mathrm{N}$ & $4 \mathrm{~h} \mathrm{BHW}$ & $\mathrm{I} \cdot 5$ & 0.80 & $34 \cdot 5$ & $\mathrm{I} \cdot 5^{\star}$ & - & 6 & 0.80 \\
\hline & $\mathrm{S}$ & $3^{\frac{3}{4}} \mathrm{~h}$ BHW & $6 \cdot 0$ & 0.498 & $35 \cdot I$ & $\mathrm{I} \cdot 3^{\star}$ & - & 8 & 0.498 \\
\hline \multirow[t]{3}{*}{ I8. v. 53} & S & $\frac{1}{2} \mathrm{~h}$ AHW & - & - & - & - & - & 6 & 0.67 \\
\hline & $\mathrm{N}$ & $\frac{3}{4}$ h AHW & 一 & - & - & 一 & - & 5 & $0.7 I$ \\
\hline & $M$ & I $\frac{3}{4}$ h AHW & - & - & - & - & - & 4 & 0.97 \\
\hline \multirow[t]{4}{*}{ I9. v. 53} & C & $3 \frac{1}{2} \mathrm{~h}$ AHW & - & - & - & - & - & 2.5 & $2 \cdot 26$ \\
\hline & $\mathrm{T}$ & $4 \mathrm{~h}$ AHW & - & - & - & - & - & $I \cdot 5$ & 2.97 \\
\hline & P & $4 \frac{1}{h} \mathrm{AHW}$ & - & - & - & - & - & $\begin{array}{l}I \cdot 33 \\
\end{array}$ & 4.60 \\
\hline & & 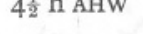 & & - & - & - & - & 0.75 & $6.4 \mathrm{I}$ \\
\hline \multirow[t]{5}{*}{ 9. vii. 53} & TA & $\mathrm{I}_{4}^{\frac{1}{4}} \mathrm{~h}$ AHW & $3 \cdot 0$ & $I \cdot 69$ & - & $9 \cdot 6$ & - & - & - \\
\hline & TB & $\mathrm{I}_{2}^{\frac{1}{2}} \mathrm{~h} \mathrm{AHW}$ & $\begin{array}{l}3.0 \\
9.0\end{array}$ & $\begin{array}{l}2 \cdot 04 \\
2 \cdot 48\end{array}$ & - & $\begin{array}{r}7 \cdot 0 \\
10.4\end{array}$ & - & - & - \\
\hline & TC & AHW & $7 \cdot 5$ & $2 \cdot 70$ & 一 & 16.7 & - & - & - \\
\hline & TD & $3 \mathrm{~h} \mathrm{AHW}$ & 3.0 & $4 \cdot 2$ & - & $27 \cdot 3$ & - & - & - \\
\hline & TE & $3 \frac{1}{2} \mathrm{~h} \mathrm{AHW}$ & 6.0 & $3 \cdot 7$ & - & $2 \mathrm{I} \cdot 2$ & - & - & - \\
\hline
\end{tabular}




\section{Determination of Suspended Solid Matter}

The water samples were taken to the laboratory and filtered within $48 \mathrm{~h}$ through 'Gradocol' nitro-cellulose membranes, as described by Armstrong \& Atkins (1950), of average pore diameter $\mathrm{I} \cdot 3$ to $\mathrm{I} \cdot 6$ microns, using an Elford

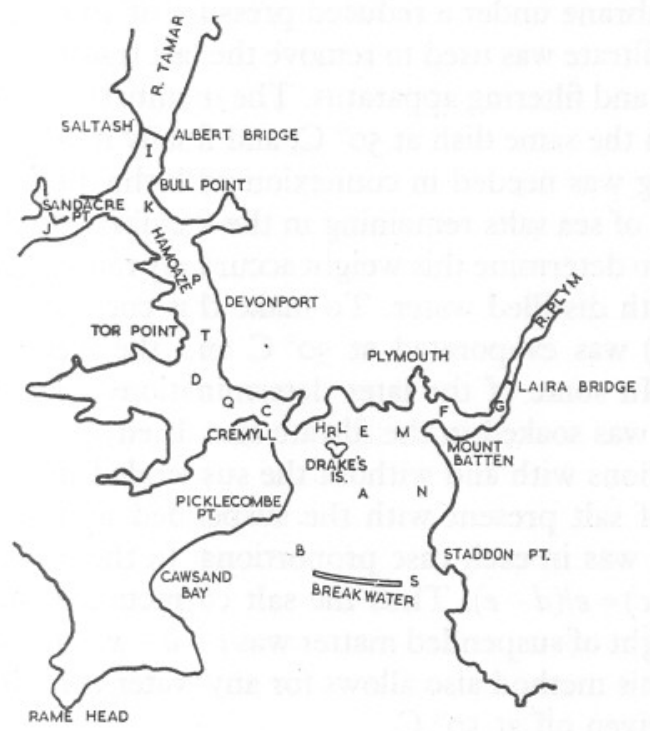

Fig. 4. Plymouth Sound and Hamoaze.

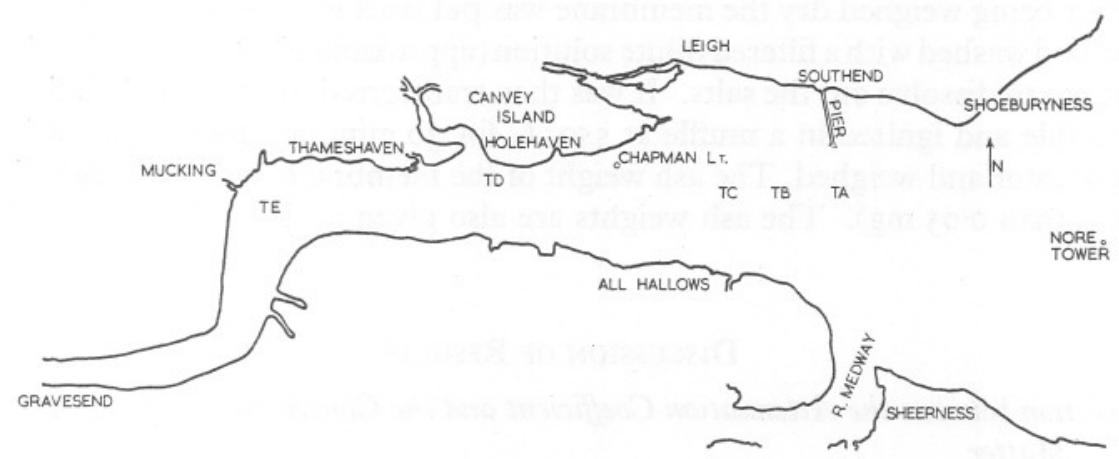

Fig. 5. Mouth of the River Thames.

filtering equipment. The samples were kept in the dark before being filtered to prevent the growth of algae. One of the filtrates was filtered a second time through a 0.6 micron membrane. Less than $0.05 \mathrm{mg}$ was obtained from 21 . of filtrate, indicating that the weight of solid matter passing through the $\mathrm{I} \cdot 6$ micron pores was negligible. 
The technique used to determine the weight of dry solid matter was as follows. The membranes which were supplied immersed in water were first dried to constant weight $(a)$ on porcelain dishes at $50^{\circ} \mathrm{C}$. According to the Wright-Fleming Institute this does not materially alter the pore size of the membranes used. A measured volume of $\mathrm{I}$ or 21 . of the water was then filtered through the membrane under a reduced pressure of about I $_{5}$ in. of mercury. A portion of the filtrate was used to remove the last traces of solid matter from the sample bottle and filtering apparatus. The membrane was weighed wet $(b)$, and then dried on the same dish at $50^{\circ} \mathrm{C}$, and finally it was weighed again $(c)$. The wet weighing was needed in connexion with the method of allowing for the small amount of sea salts remaining in the membrane after drying. It was considered safer to determine this weight accurately rather than to try and wash away the salts with distilled water. To make this correction a known weight of the filtrate $(d)$ was evaporated at $50^{\circ} \mathrm{C}$ and the weight of residual salt determined (e). In some of the later determinations a clean dry membrane of the same kind was soaked in the filtrate and dried, so as to make sure that the drying conditions with and without the suspended matter were identical. Let the weight of salt present with the suspended matter $=x$. The loss of weight on drying was in each case proportional to the weight of salt present and hence $x /(b-c)=e /(d-e)$. Thus the salt correction $x$ was calculated and the corrected weight of suspended matter was $c-a-x$. In addition to correcting for the salts this method also allows for any water combined with the salts which was not driven off at $50^{\circ} \mathrm{C}$.

Some ash weight determinations were also made by the following method. After being weighed dry the membrane was put back into the filtering apparatus and washed with a filtered dilute solution (approximately $\mathrm{N} / 2$ ) of ammonium nitrate to dissolve out the salts. It was then transferred to a weighed platinum crucible and ignited in a muffle at $550^{\circ} \mathrm{C}$ for $30 \mathrm{~min}$, and finally cooled in a desiccator and weighed. The ash weight of the membrane itself was negligible (less than $0.05 \mathrm{mg}$ ). The ash weights are also given in Table I.

\section{Discussion OF Results}

\section{Relation between the Attenuation Coefficient and the Concentration of Suspended Matter}

In Fig. 3 the experimental results are shown plotted in the form of the attenuation coefficient $\mu$ against the concentration of suspended matter in $\mathrm{mg} / 1$., approximately equal to parts per million (p.p.m.). The attenuation coefficient was deduced from the hydrophotometer readings by the use of equation (2).

For the suspensions of kaolin and mud in tap water the attenuation is seen to be a linear function of concentration apart from a slight unexplained curva- 
ture near the origin. For sea water the points are much more scattered, as might be expected in view of the variations in the nature of the suspended material from place to place, and the experimental errors involved in filtering and weighing. The curve in the figure has been drawn so as to represent, as nearly as possible, the average properties of the different samples investigated. It is clear from the results that the attenuation coefficient is approximately proportional to the concentration only for the lower concentrations and rises less steeply than for the freshwater suspensions, and less and less steeply as the turbidity increases. These results may doubtless be attributed to variations in the nature or particle size distribution of the suspended material. As regards the effect of variations of particle size, the total projected area of the particles for a given amount of material decreases as the particle size increases, i.e. as flocculation proceeds. It is to be expected that the suspended matter present in salt water is in a more flocculated state than suspensions made up in fresh water.

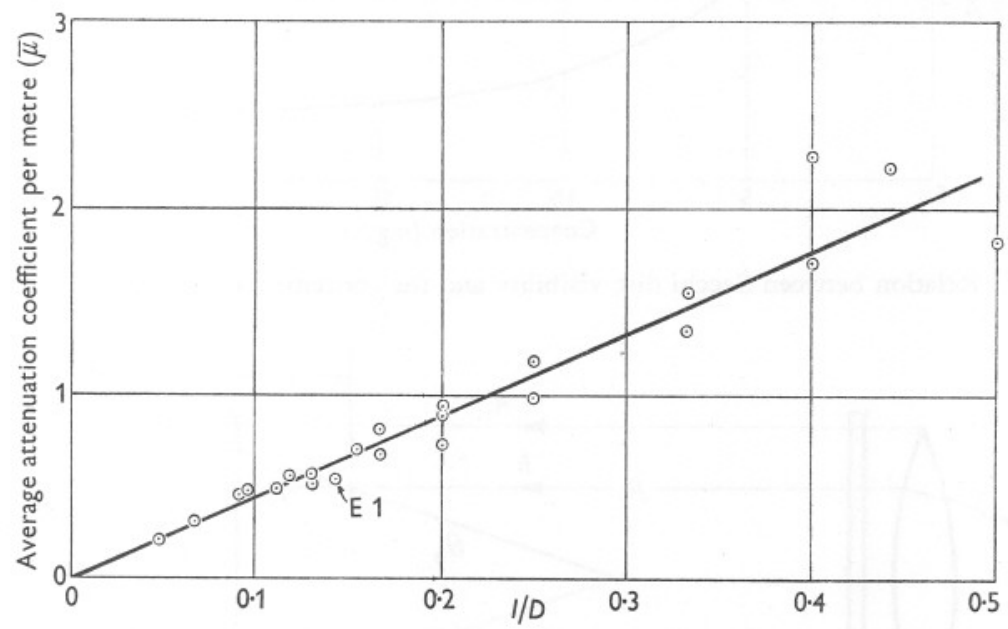

Fig. 6. Relation between attenuation coefficient per metre and Secchi disc visibility.

The point marked E I in Fig. 3 was for an observation made at Hydrographic Station EI, $c a$. Io miles south-west of the Eddystone, when there happened to be an exceptionally large growth of plankton containing much Phaeocystis. The light transmission was $75 \%$ per half metre, and the concentration of dry matter came out to be $3.5 \mathrm{mg} / 1$. The usual concentration for this value of light transmission was about $2 \mathrm{mg} / 1$. near the land in the neighbourhood of Plymouth. The weight of the EI material after ignition was only $0.3 \mathrm{mg} / 1$., showing that little material apart from the organic matter was present, as would be expected so far from land. 
Relation between the Attenuation Coefficient and Visibility of a Secchi Disc

For the positions where the Secchi disc reading $D$ metres was observed the mean attenuation coefficient $\bar{\mu}$ between the sea surface and depth $D$ was calculated. The results covered the range $D=2 \mathrm{I} \mathrm{m}$ to $0.75 \mathrm{~m}$, corresponding to

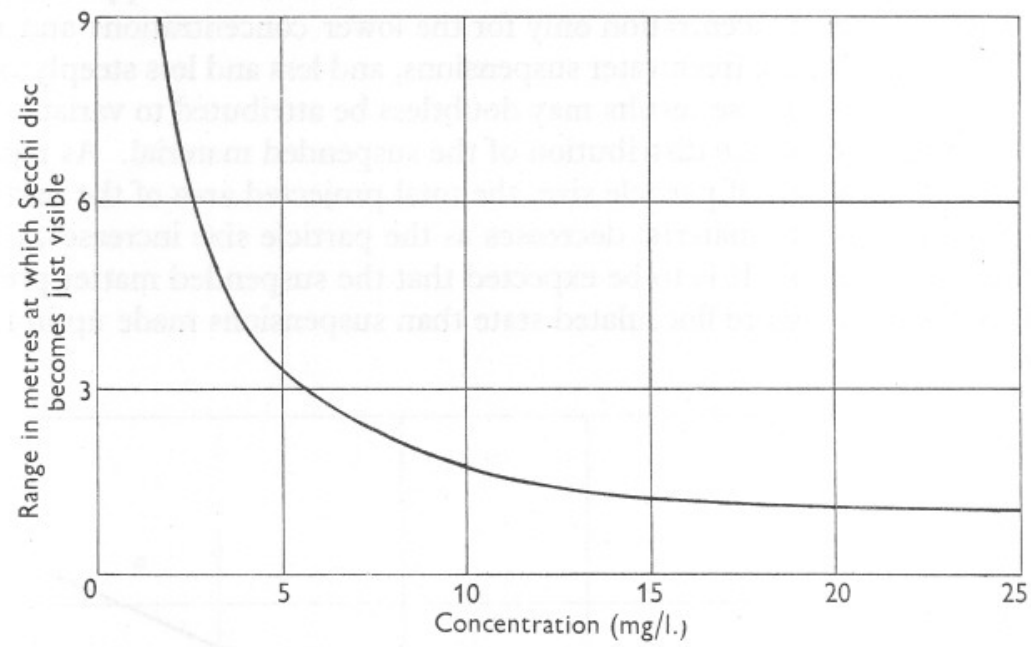

Fig. 7. Relation between Secchi disc visibility and the concentration of suspended matter.

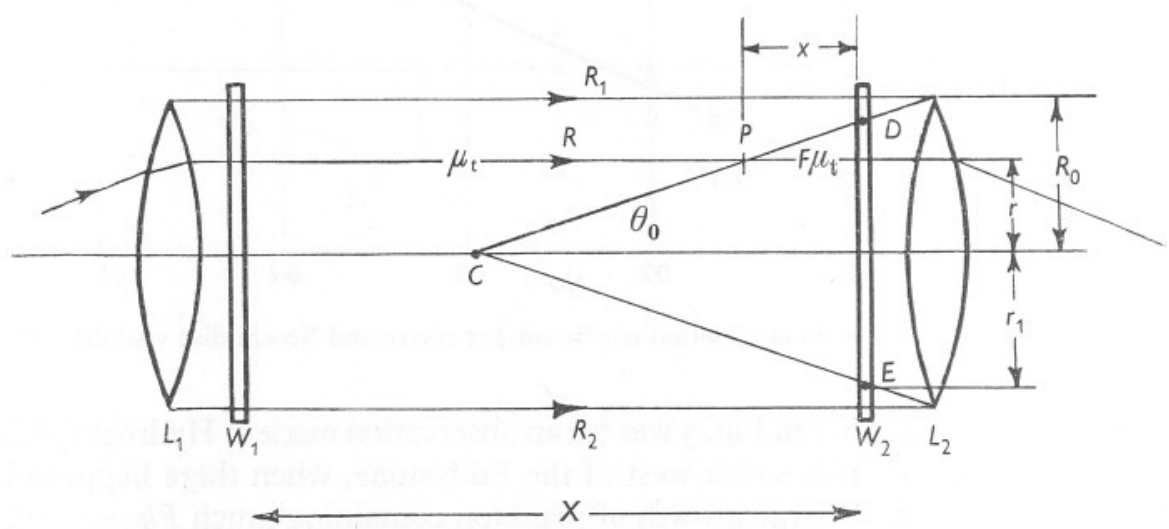

Fig. 8. Limiting cases of collected scattered light.

$\bar{\mu}=0.2 \mathrm{~m}^{-1}$ to $6.4 \mathrm{~m}^{-1}$ and the best relation to fit them all was found to be $\bar{\mu}=(4.75 \pm 0.08) / D^{(1.04 \pm 0.02)}$. If the few results for the very turbid water $(\bar{\mu}>3)$ were excluded, a satisfactory agreement was obtained with the simple formula $\bar{\mu} D=K$ (a constant) with the value $K=4.38 \pm 0 \cdot$ I. Fig. 6 shows $\bar{\mu}$ plotted against $\mathrm{r} / D$ together with the straight line $\bar{\mu}=4 \cdot 38 / D$. 
For Station EI, where the turbidity was mainly due to plankton, the observed Secchi visibility was somewhat less than that predicted from a hydrophotometer reading using the above formula. The actual Secchi disc reading was $7 \mathrm{~m}$, whereas the value deduced from the hydrophotometer reading was $8 \mathrm{~m}$. However, this difference may not be significant in view of the rather large experimental errors associated with a single observation.

In Fig. 7 is shown the relation between Secchi disc visibility and the concentration of suspended matter, deduced by combining the results of Figs. 3 and 6 .

\section{SUMMARY}

For suspensions of kaolin or Thames mud in fresh water the attenuation coefficient per metre of an approximately parallel beam of light from a tungsten filament lamp was found to be a linear function of the concentration of suspended matter. It reached the value $5 \mathrm{~m}^{-1}$ for approximately $10 \mathrm{mg} / \mathrm{l}$. of suspended matter. For sea and estuarine waters near Plymouth and in the Thames Estuary the attenuation coefficient, measured in situ, was only about $2.5 \mathrm{~m}^{-1}$ for Io $\mathrm{mg} / 1$. and it increased still less rapidly for higher concentrations, reaching only $4.5 \mathrm{~m}^{-1}$ at about $28 \mathrm{mg} / 1$. The concentration of suspended matter was determined by filtering water samples through ' $G$ radocol' membranes, drying the membranes at $50^{\circ} \mathrm{C}$, and correcting for the quantity of inorganic salts present with the suspended matter.

The Secchi disc visibility was inversely proportional to the attenuation coefficient over the range $I \cdot 5$ to $2 I$ metres.

\section{REFERENCES}

Armstrong, F. A. J. \& Atkins, W. R. G., I950. The suspended matter of sea water. F. mar. biol. Ass. U.K., Vol. 29, pp. 139-43.

Atkins, W. R. G., Jenkins, P. G. \& WARREN, F. J., I954. The suspended matter in sea water and its seasonal changes as affecting the visual range of the Secchi disc. F. mar. biol. Ass. U.K., Vol. 33, pp. 497-509.

Hulbert, E. O., 1945. Optics of distilled and natural water. F. opt. Soc. Amer., Vol. 35, pp. 698-705.

Jenkins, F. A. \& Bowen, I. S., I946. Transparency of ocean water. F. opt. Soc. Amer., Vol. 36, pp. 6I7-23.

Jerlov, N. G., I95I. Particle distribution in the ocean. Rep. Swedish deep-sea Exped., Vol. 3, pp. 73-97.

Pettersson, H., I934. A transparency-meter for sea-water. Göteborgs VetenskSamh. Handl., Ser. B, Bd. 3, No. 8, 17 pp. (Medd. fr. Göteborgs Högskolas Ocean. Inst., No. 7.)

Poole, H. H. \& Atkins, W. R. G., I928. Further photo-electric measurements of the penetration of light into sea water. F. mar. biol. Ass. U.K., Vol. I5, pp. 455-83.

WaLton, W. H., I947. In Symposium on Particle Size Analysis, pp. I4I-2. London: Institution of Chemical Engineers. 


\section{APPENDIX \\ The EFFect of Forward SCATtered Light ON THE Readings of a Light TRANSMission Meter}

This appendix refers to any light transmission meter having an optical system similar to that shown in Fig. 2 (such as the A.R.L. hydrophotometer).

Owing to the finite size of the stop $S_{2}$ which cannot be reduced without loss of sensitivity a certain amount of light scattered by the particles of the turbid medium in forward directions (i.e. in nearly the same direction as the incident light) reaches the detector, and thus the measured light transmission is higher than it would be if the hole were negligibly small.

An accurate theoretical calculation of the effect for a given instrument would involve a long computation for each particle size and would have very little value in practice as a method of correcting the reading because the particle size distribution in the turbid medium is very rarely known. It is, however, desirable to know the order of magnitude of the error, and it is now shown how to determine limits within which the error lies for a given particle size. An experimental determination of the effect in a given turbid medium would involve measuring the angular distribution of the scattered light.

\section{Angular Distribution of the Scattered Light}

It can readily be shown that if the lens $L_{2}$ has no stopping effect the effective semiangle subtended by the photocell $C_{2}$ is the same at all points in the absorbing medium, equal to $\theta_{0}=s / f$, where $s$ is the radius of the stop $S_{2}$ and $f$ the focal length of the lens $L_{2}$.

It has been pointed out by Walton (I947) that the angular distribution of the scattered light may be calculated by the theory of Fraunhofer diffraction and without recourse to electromagnetic theory for the case of opaque particles which are large compared with the wave-length. According to Walton, if the incident parallel beam is of intensity I lumen $/ \mathrm{cm}^{2}$ and an opaque particle of radius $a$ (where $a$ is small compared with the diameter of lens $L_{2}$ but large compared with the wave-length $\lambda$ ) is placed in front of lens $L_{2}$ it will intercept a quantity of light $\pi a^{2}$ lumens and also diffract a quantity of light which will be distributed over the area of $S_{2}$. The total diffracted light is shown to be also equal to $\pi a^{2}$ and the fraction of this lying within a circle of radius $s$ is

or

$$
\mathrm{I}-J_{0}^{2}(2 \pi a s / f \lambda)-J_{1}^{2}(2 \pi a s / f \lambda),
$$

where

$$
\mathrm{I}-J_{0}^{2}\left(z_{0}\right)-J_{1}^{2}\left(z_{0}\right),
$$

$$
z_{0}=2 \pi a \theta_{0} / \lambda \text { since } \theta_{0}=s / f \text {, }
$$

where $J_{0}$ is the Bessel function of zero order, and $J_{1}$ is the Bessel function of the first order.

The parameter which expresses the proportion of scattered light collected is the ratio per particle:

$$
\frac{\text { light intercepted }+ \text { light scattered outside the cone of semi-angle } \theta_{0}}{\text { light intercepted }+ \text { total light scattered }} \text {. }
$$

This will be called the factor of merit $F$. Thus for opaque particles

$$
\begin{aligned}
F & =\frac{\pi a^{2}+\pi a^{2}\left\{J_{1}^{2}\left(z_{0}\right)+J_{0}^{2}\left(z_{0}\right)\right\}}{2 \pi a^{2}} \\
& =\frac{1}{2}\left\{\mathbf{I}+J_{1}^{2}\left(z_{0}\right)+J_{0}^{2}\left(z_{0}\right)\right\} .
\end{aligned}
$$


It is clear that for a perfect instrument $\left(\theta_{0}=0\right)$ in which none of the scattered light is collected, $F=\mathrm{I}$. If some of the scattered light is collected $F$ lies between I and 0.5 for opaque particles and may even fall below 0.5 for translucent particles.

\section{Finite Aperture of Lens $L_{2}$}

The effect of the finite aperture of the lens $L_{2}$ will now be considered. If a scattering particle lies near the edge of the beam, or far enough in front of lens $L_{2}$, part of the scattered light within the angle $\theta_{0}$ may be intercepted by the aperture of the lens. In Fig. $8 W_{1}, W_{2}$ represent the windows enclosing the turbid liquid, and $R_{1}, R_{2}$ are rays defining the width of the light beam. Only particles lying within the cone $C D E$ can contribute the full amount of forward scattered light, and particles at other points in the liquid have part of the scattered light intercepted by the aperture of the lens $L_{2}$. The amount of scattered light collected is obviously $(a)$ less than that due to the whole volume of turbid liquid, and $(b)$ greater than that due to the particles in the cone $C D E$. It is therefore possible in a simple way to set limits to the amount of scattered light collected; an exact solution would involve computing the proportion of scattered light collected from each particle outside the cone.

Let $\mu_{t}$ be the true attenuation coefficient of the turbid medium (as measured with a perfect instrument);

$\mu_{a}$ be the attenuation coefficient as measured if all the scattered light were received by the photocell (case $a$ );

$\mu_{b}$ be the attenuation coefficient as measured if only scattered light from the cone $C D E$ were received by the photocell (case $b$ );

$\mu$ be the measured attenuation coefficient with the actual instrument.

Then the value of $\mu$ corresponding to a certain value of $\mu_{t}$ will lie between the limits $\mu_{a}$ and $\mu_{b}$.

Calculation of $\mu_{a}$ and $\mu_{b}$ corresponding to a given value of $\mu_{t}$

$\mu_{a}$ is simply related to $\mu_{t}$. Thus: $\mu_{a}=F \mu_{t}$.

To find $\mu_{b}$ consider a typical ray such as $R$ in Fig. 8 which is for part of its path outside the cone $C D E$ and for part inside $C D E$. The coefficient $\mu_{b}$ is deduced by assuming the attenuation coefficient to be $\mu_{t}$ for the first part of the path and $F \mu_{t}$ for the latter part.

It is then fairly simple to show that

$$
\begin{aligned}
\exp \left(-X \mu_{b}\right)=\left(\mathrm{I}-r_{1}^{2} / R_{0}^{2}\right) \exp \left(-X \mu_{t}\right)+\frac{2 \exp \left[\mu_{t}\left\{-X+(\mathrm{I}-F) r_{1} \cot \theta_{0}\right\}\right]}{R_{0}^{2} \mu_{t}^{2}(\mathrm{I}-F)^{2} \cot ^{2} \theta_{0}} \\
\times\left\{\mathrm{I}-\left[\mathrm{I}+\mu_{t}(\mathrm{I}-F) r_{1} \cot \theta_{0}\right] \exp \left[-\mu_{t}(\mathrm{I}-F) r_{1} \cot \theta_{0}\right]\right\},
\end{aligned}
$$

where $X$ is the path length of the beam, $R_{0}$ is the radius of the beam, and $\theta_{0}=s / f$.

\section{Application to the A.R.L. Hydrophotometer}

The important dimensions are as follows:

$\begin{array}{ll}\text { Path length of beam in liquid } & X=50 \mathrm{~cm} \\ \text { Radius of beam } & R_{0}=2.25 \mathrm{~cm} \\ \text { Radius of aperture in stop } S_{2} & s=0.3 \mathrm{~cm} \\ \text { Focal length of lens } L_{2} & f=5.3 \mathrm{~cm} \\ & \theta_{0}=3.2^{\circ}\end{array}$

Assume a mean wave-length $=5500 \AA$. 
Table II shows the values of $\mu_{a}$ and $\mu_{b}$ calculated from equations (A 2 ) and (A 3 ) respectively, corresponding to $\mu_{t}=3.0 \mathrm{~m}^{-1}$ for opaque particles of different diameters. For a constant size of particle $\mu_{a}$ is proportional to $\mu_{t}$, equation (A 2), and it has been found by calculation that $\mu_{b}$ is also proportional to $\mu_{t}$ with considerable accuracy.

TABLE II

Particle diameter (microns) $2 \cdot 5$ I0 $+5$

If $\frac{1}{2}\left(\mu_{a}+\mu_{b}\right)$ be taken as an approximate measure of $\mu$ a factor can be derived which will give some measure of correction for the inclusion of scattered light. This correction factor $k$ is given by $2 \mu_{t} /\left(\mu_{a}+\mu_{b}\right)$ approximately, and its value for each of the particle sizes computed is shown in Table II. If $k$ be taken as $\mathrm{I} \cdot 3$ the error in $k$ is not likely to exceed $\pm 20 \%$ over the size range 5 microns and upwards. For particle sizes much smaller than 5 microns the Fraunhofer diffraction theory does not apply and the electromagnetic theory of scattering must be used to determine the value of the correction factor. 